\title{
New anthropometric measure for better fit of women skirts/trousers between the waist and maximum hip level
}

\author{
Tanja PODBEVŠEK
}

University of Ljubljana / Faculty for Natural Sciences and Engineering, Department of Textiles, Graphic Arts and Design / Snežniška 5, 1000 Ljubljana, Slovenia

Corresponding Author: Tanja Podbevšek, tanja.podbevsek@a.ntf.uni-lj.si

\begin{abstract}
The aim of the work was to improve the development of a basic pattern block with modelling a curve of the side seam over the hip of the skirt or trousers. The area between the waist and the maximum hip line is completely overlooked as none of the pattern construction systems give precise instructions. To support the idea, data from anthropometric measurements of 162 young Slovenian women between the ages of 18 and 27 were used. The shape of the curve at the side seam of the skirt was quantified using a hip curve distance (HCD) based on a new measurement: an additional girth measurement $11 \mathrm{~cm}$ below the waist girth. The HCD range of 4,77 cm indicated significant differences in the shape of the curve at the side seam of the skirt that could not be neglected.
\end{abstract}

\author{
ARTICLE HISTORY \\ Received: 08.01.2021 \\ Accepted: 15.06.2021

\section{KEYWORDS} \\ Anthropometric measurement, \\ skirts, trousers, waist and \\ (maximum) hip height, waist \\ and (maximum) hip girth
}

\section{INTRODUCTION}

Skirts and trousers are an indispensable part of every modern woman's wardrobe. Their visual forms have constantly changed throughout history for various reasons. The result has been skirts and trousers of various lengths, widths, shapes of their silhouettes, etc. One of their most important features was a level of the waist band, which in the past changed its height in the fashion collections of various designers and clothing manufacturers. The reasons for changing its height were due to the desire to emphasize or replicate the ideal shape of women's waist, hips and buttocks, which was considered beautiful in certain fashion periods [1]. Modern times are no different in this regard. The difference we notice today is due to the contemporary society with pronounced individualism and diversity of lifestyles of different target groups in the global market. Consequently, the fashion industry offers many different beauty ideals of women and, consequently, very different fashionable clothes, giving each target group of consumers the opportunity for individual expression. At the beginning of the 21 st century, the popularity of fashionable clothing with significantly lowered waist bands was noted, especially among younger generations. In the following years, the waistband height of trousers and skirts increased, differently for different target customer groups, and these variations in waistband height will continue in the future.

On the other hand, the proportions and anthropometric measurements of the real body $[2,3,4,5,6]$ are also changing due to aging [7], practice of certain sports activities [8], obesity [9] or other changes in people's lifestyle. For this reason, it is necessary to constantly update standards in the clothing industry through improved anthropometric measurement procedures and methods $[10,11,12,13,14,15]$.

The described changes in fashion due to the waistband height of skirts and trousers, together with the changes in women's real body measurements, pose a great challenge for apparel manufacturers to create a basic pattern block of skirts and trousers that fit well around the body of their target groups. Researchers emphasize that customer satisfaction is related to the selection and purchase of clothing in the right size [16], as a good fit of the garment contributes to the wearer's self-confidence and comfort

To cite this article: Podbevšek T. 2021. New anthropometric measure for better fit of women skirts/trousers between the waist and maximum hip level. Tekstil ve Konfeksiyon, 31(2), 129-136. 
[17]. Dissatisfaction with fit is one of the most frequently cited problems when buying ready-made clothing [18]. As some researchers point out [19], fit problems with skirts are most likely to occur when the difference between hip and waist circumference is large.

The fit of clothing is closely related to the values of body measurements taken from measurement tables provided by clothing production companies, which are incorporated into the basic pattern blocks of clothing.For example, the waistto-hip distances (WtH) for a group size may differ significantly, affecting the shape of the curved lines of the side seams above the maximum hip height level [6]. However, the shape of the curved lines of the side seams must not be defined by two points, but by at least three.Every contemporary construction system includes waist and (maximum) hip girth in its measurement tables, but none of them gives precise instructions about the shape of the curve at the side seam for a well-fitting pattern block [20,21,22,23,24,25,26,27]. Therefore, in this paper, we suggest measuring an additional girth between the waist and the maximum hip line to add the third point.

The shape of the side seam curve is especially critical for low-waistband trousers/skirts because it must compress the body enough at the waistband level and also around the hips to keep the clothing on the body when a person walks, sits down, leans forward, etc. The shape of the side seam curve is also important for trousers and skirts with higher waistbands from the natural waist level, especially for tighter fitting styles when the trousers need to follow the body shape of the wearer's waist and hips. For this reason, in order to develop basic block patterns of skirts or trousers, pattern developer should know the value of the girth at the level of the lowered waistband of trousers or skirts of their target customer group. Otherwise, it would be a guess to achieve a good fit of the garment at the level of the said waistband. This is often left to pattern developers, who are usually responsible for selecting or developing the appropriate basic block pattern of skirts or trousers, from which they then create new fashion collections. If the shape of the side seam curve is not chosen correctly from the set of possible curves (Figure 1), this can have a negative effect on the sale or return of garments when sold online.

To create a well-fitting skirt basic block pattern, the pattern developer first needs information about the real values of the average bodies of the selected target group. Without additional information, the pattern developer is forced to randomly determine the shape of the side seam curve between the waist and the maximum hip girth line, which can vary greatly in the ready-made clothing industry or for individual bodies in made-to-measure smaller businesses. It is very important that these values are measured using a measurement methodology that is consistent with the actual progression of development of the basic pattern blocks of selected garments, which has also been pointed out by other researchers $[13,6]$. With the publication of the new standard 8559-1 [28] in 2017, an attempt was made to standardize the measurement methodology for all measurements, which should be important for the development of garment pattern blocks and would allow comparability of measurement results from different anthropometric measurement surveys around the world.

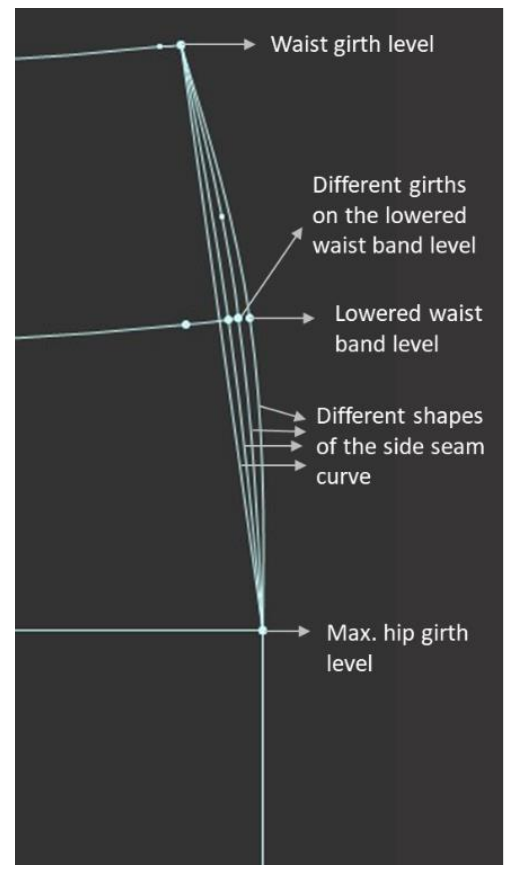

Figure 1. Without additional information, pattern developers are forced to randomly determine the shape of the side seam curve between the waist and the maximum hip girth line, which can vary greatly.

This paper aims to critically discuss the methodology for measuring additional girths between the waist and the maximum hip level from ISO 8559-1:2017. A new measure is proposed to develop a well-fitting skirt basic pattern block between the waist and the maximum hip level, shortening and simplifying the anthropometric measurement procedure proposed in the standard ISO 8559-1.

In the past, to create a well-fitting skirt basic block pattern, the pattern developer usually needed the measurements of the waist girth (WG), the maximum hip girth (MaxHG, as the maximum horizontal girth of the body below the hip level [28]), a vertical distance from the waist level to the maximum hip girth level (WtoMHGD, as the former waistto-hip distance), and the length of the skirt (Lskirt). Even ignoring the problem of using different measurement methods in practice, these measurements are only partially adequate for the skirts or trousers whose waistband is exactly at the waist level specified in 8559-1 (midway between the lowest point of the rib and the highest point of the bone on the side of the body [28]). The degree of fit across the hips in this case is related to the real value of the waist-to-hip distances of the customers [6], but also to the proper selection of the curve shape of the side seam, which is related to the curve shape of the hips and thighs in the front view of the selected body, which is the subject of research in this paper. If the waistband is lower than the natural waist level, the girth at the level of the skirt or 
trousers waistband becomes even more important, rather than the waist girth on the natural waist level of the body. There is a complete scarcity of published measurement tables which would include additional girths between the waist and hip level that would give the pattern developer an important information about body circumferences at the level of the skirt or trousers waistband, unless the waistband is placed exactly at the level of the natural waistline.

Most often, the pattern developer solves this problem by cutting away a portion of the basic skirt block pattern from the waist line parallel down (not always parallel), as much as the fashion designer has determined by his/her technical sketch of the new model of the skirt in the latest fashion collection (Figure 2).

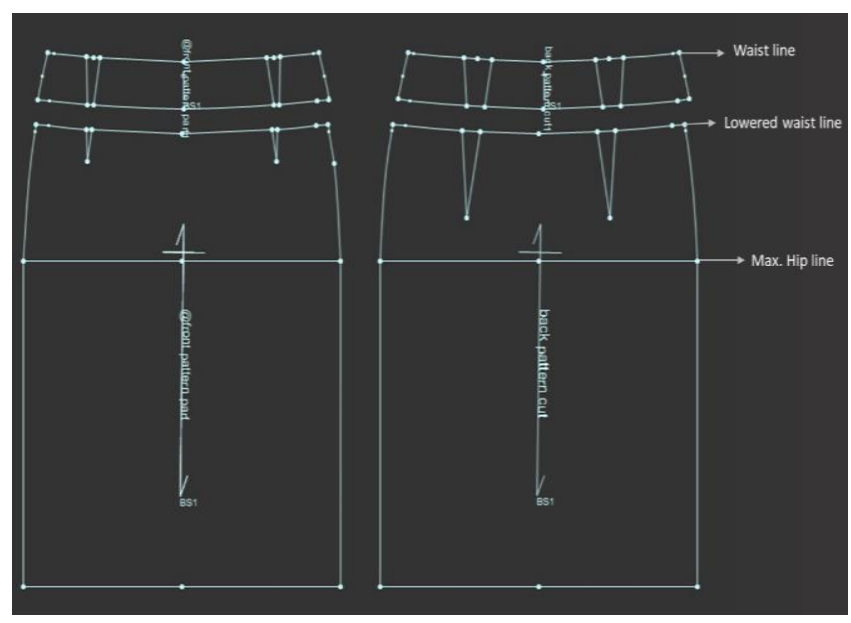

Figure 2. A parallel part of the basic block pattern which is usually cut away when making the pattern with the lowered waist band, e.g., $6 \mathrm{~cm}$.

This methodology would be acceptable if the curve of the side seam on the basic pattern block of the skirt or trousers between the waist line and the maximum hip line truly reflected the shape of the hips of the selected target consumer group. However, because the aforementioned shape of the curve is generally blindly selected by the pattern developer and often manually drawn using commercially available rulers or various tools included in a computerized apparel pattern development system, the shape of the curve is often inappropriate. With a poorly chosen curve between the waist and the maximum hip line, skirts or trousers will be too tight or in most cases too wide at the new line of the lowered waistband (Figure 3).

To solve the problem of proper curve of the side seam, at least one additional horizontal girth and its height (for example, vertical distance from the line of the waist girth ) between the waist and the line of the maximum hip girth line would help to fit well to the body of the selected consumer target group or individual body. A new version of the 8559 standard (8559-1) in 2017 addressed the lack of additional measurements (body girths measures) between the waist and maximum hip level and proposed three new girths: top hip girth (THG) as horizontal girth of the body measured at the top hip height level (THH) as a midway between the waist height and the hip height, upper hip girth (UHG) as a horizontal girth of the body measured at upper hip height level (UHH) as a midway between the top- hip height and the waist height, and hip girth (HG) as a horizontal girth of the body measured at the hip height level $(\mathrm{HH})$ as the vertical distance between the hip height and the ground [28].

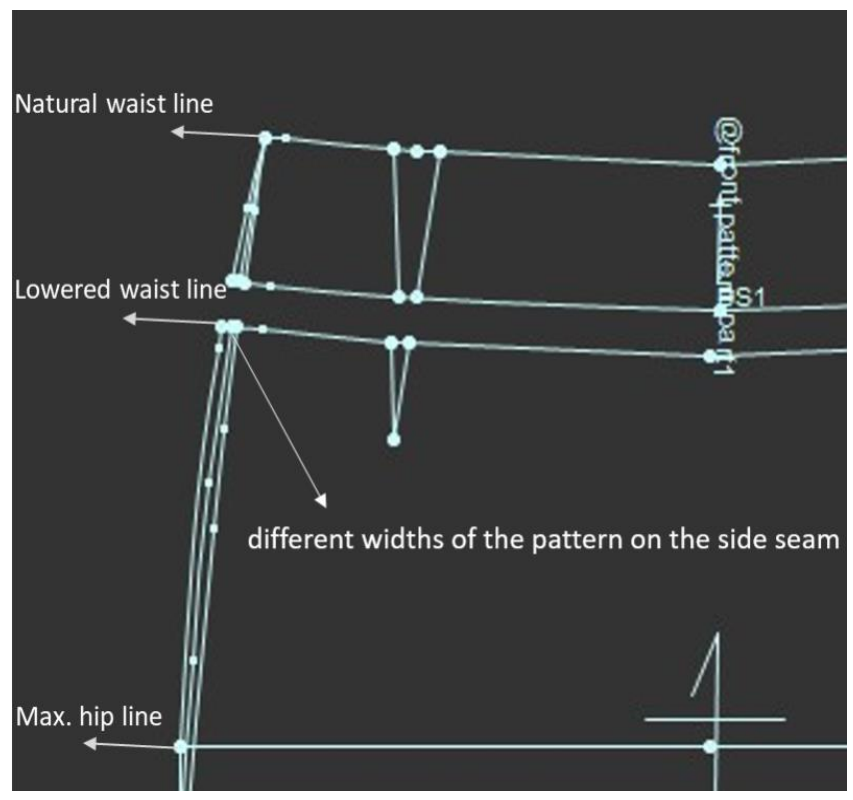

Figure 3. The influence of choosing different curves at the side seam on the width of the skirt basic pattern block on the lowered waistline

Despite the fact that the standard accurately describes their measurement methodology along with the measurement locations, these three new girths are determined by the proportion of the distance between the waist and the hip level, where the hip level is newly described as the level of the greatest projection at the back of the body (buttocks) [28]. The hip girth defined in this way loses the most important role in the development of skirt or trouser pattern blocks, because the most important measurement undoubtedly remains the maximum hip girth (MaxHG). This is the girth that ensures women to put on tight skirts or trousers over the maximum circumference of their hips, buttocks or thighs. The maximum hip girth must be determined by measurement and not by sight. In most cases, it is below the described hip girth level defined by standard 8559-1 [28]. To measure an additional girth between the waist and the maximum hip height level as defined in standard 8559-1, we must first define the hip height level and then additionally either top hip height level for measuring top hip girth or the upper hip height level for measuring upper hip girth. In this way, we have to measure at least 7 measures (WG -waist girth, MaxHG-maximum hip girth, WH -waist height, MaxHGH-maximum hip girth height, HH-hip height, THH-top hip height and THG-top hip girth or UHH-upper hip height and UHG-upper hip girth). 
In order to reduce the number of measures and thus shorten and simplify the measurement procedure with the same or even better effect, this paper introduces a new measure for all different groups (sizes) of women, the so- called additional girth (AG) between the waist level and maximum hip girth level, on the standard distance of $11 \mathrm{~cm}$ from the natural waist line parallel downwards. In this way, only 5 measurements are needed (WG -waist girth, MaxHG-maximum hip girth, WH -waist height, MaxHGHmaximum hip girth height and AG -additional girth) to create a well-fitting basic block pattern for the skirt. There are several reasons to measure AG at the suggested distance from the natural waist line. The first is that the length of the front dart on the skirt or trousers in most contemporary construction systems is no more than 11 centimeters [21,22,23,24,26,27,28], so we avoid drawing in the front dart if we decide to develop the basic pattern block for the skirt or trousers with lowered waistband from the beginning. Second, that this height approximately coincides with the change in body shape in the side view because it is approximately on the lower edge of the hip bone (iliac crest). And third, most importantly, that this measure is approximately midway between the waist line and the maximum hip line [6,24]. An additional reason for the introduction of the new measure AG is that the UHG and THG measures proposed in the 8559-1 standard are very close to the natural waist line, and therefore another measurement closer to the maximum hip girth line is necessary to ensure the least possible error when drawing the side seam curve across the hip bulge. Finally, the $11 \mathrm{~cm}$ distance is short enough to measure it with a tape measure and obtain sufficiently accurate results during the manual anthropometric procedure.

Another important measure that requires attention is the waist to maximum hip girth distance (WtoMaxHGD) as the vertical distance between waist level and maximum hip girth level. It should not be mixed with the side waist-to-hip distance (SWtoH) from 8559-1 standard or the waist-to-hip distance from the older version of that standard for two reasons. The first reason is that $\mathrm{SWtoH}$ is measured on the side of the body from waist level to hip level along the body shape line [28] and not as a vertical distance, and the second reason is that $\mathrm{SWtoH}$ is measured to hip level and not to maximum hip level. Both of the described reasons are not in accordance with the basic block pattern development process for skirts in contemporary construction systems [20,21, 22,23,24,25,26,27]. To obtain the WtoMaxHGD, one should first measure the waist height (WH) as the vertical distance from the waist level to the floor and the maximum hip girth height (MaxHGH) as the vertical distance from the level of the maximum hip girth to the floor [28], and then subtract MaxHGH from WH. It is very important for pattern developers to know the correct value of WtoMaxHD distance of their consumer target group, because the value of WtoMaxHG also affects the slope of the curve of the side seam of the skirt or trousers and thus the fit of the basic pattern block of the skirt in the lowered waist band level [6] (Figure 4).

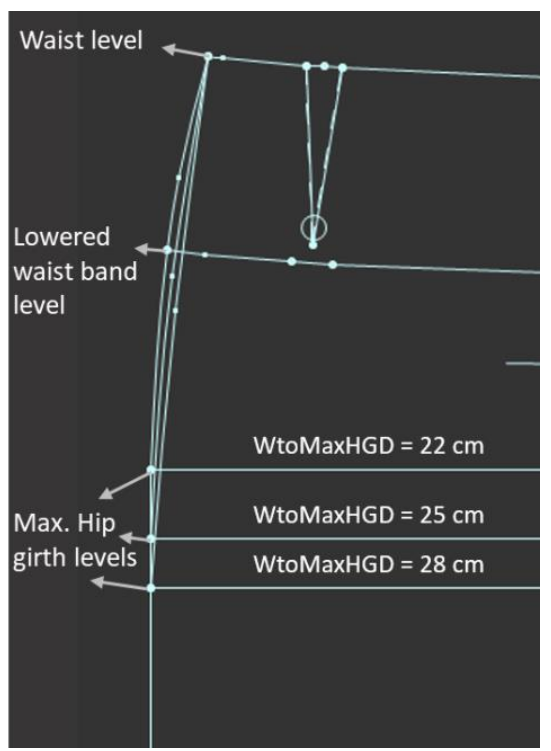

Figure 4. The influence of different values of WtoMaxHGD on the shape of the side seam curve between the waist and the maximum hip girth level

This paper presents a further development of the basic pattern block based on an additional girth that allows the curve of the side seam of the skirt or trousers to be modelled for the target group of women, and proposes an additional measure that should become part of the content of future measurement tables because of its importance for the development of well-fitting basic blocks patterns of skirts and trousers.

\section{MATERIAL AND METHOD}

\subsection{Participants}

The anthropometric research was carried out on 162 women, representing a young Slovenian female population between the ages of 18 and 27, who volunteered in the study. At the time of measurement, they were bachelor and master students at the University of Ljubljana (Slovenia). The subjects were divided into 6 groups according to the (maximum) hip girth as suggested by EN 13402-3:2017 [29], since the maximum hip girth is the most important measure in the development of basic pattern blocks for garments covering the lower body such as skirts or trousers. All the participants were well informed about the procedure of the experiment. None of them gave birth.

\subsection{Anthropometric survey}

In the experiment, the waist level (upper band) as midway between the lowest rib point and the highest point of the hip bone at the side of the body [28]); the maximum hip girth level (lower band) as the maximum horizontal girth of the body below the hip level [28] and the new level (additional distance $\mathrm{AD}$ ) between the waist and maximum hip girth level on exactly 11 centimeters lower position from the waist level (middle band) were first selected and marked with $2 \mathrm{~mm}$ wide elastic band (Figure 5). The bands were placed around the body in a way that the ellipsoid levels of 
the waist, maximum hip and the additional level in between were perpendicular to the longitudinal axis of the body. The bands did not compress the soft tissues of the body. Girts were measured exactly under the elastic bands on the marked levels.

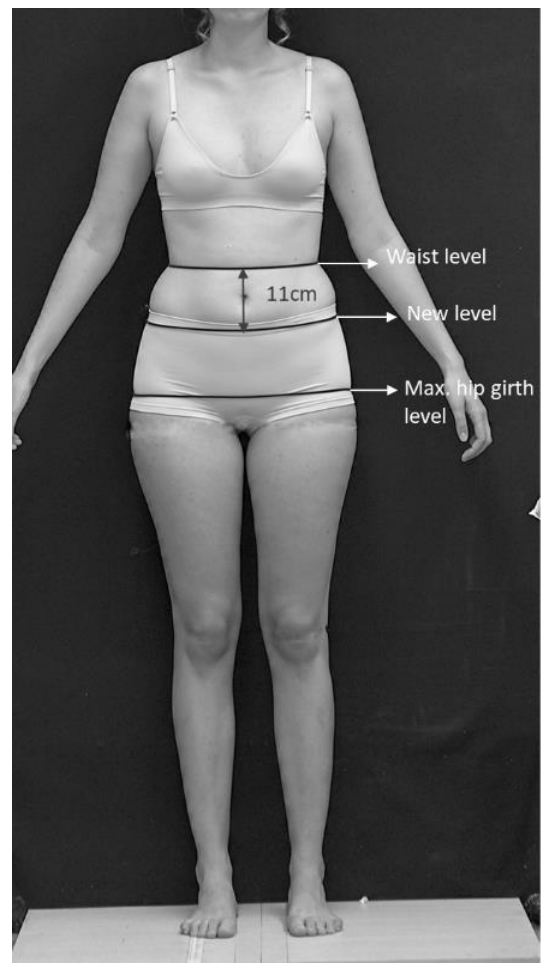

Figure 5. The waist (upper band), maximum hip girt level (lower band) and the new level (middle band) marked with elastic bands

During the measurement, the participants were standing on the levelled ground in their natural posture with their feet together and their centre of gravity evenly distributed on both legs. Their heads were aligned with the Frankfurt's line. During the measurement, they breathed normally with a relaxed abdomen, arms hanging freely down the torso or slightly raised, but in such a way that their posture or the observed body dimensions did not change. Participants were dressed in their underwear and barefoot. Survey was performed in forenoon by the same person.

Waist girth (WG), maximum hip girth (MaxHG), waist height (WH) (vertical distance from the waist level to the ground), maximum hip girth height (MaxHGH) (vertical distance from the level of maximum hip girth to the ground) and stature (S) (vertical distance from the highest point of the head in the median line to the ground) were measured according to the 8559-1 standard [28]. In accordance with the aim of the paper, the additional girth (AG) between the waist and the maximum hip level was measured $11 \mathrm{~cm}$ below the waist level.Stature and height measures (except mentioned AD) were performed with an anthropometer on the right side of the body, girths and AD were measured with the dimensionally stable tape-measure. All values were rounded up to a higher value with $0.5 \mathrm{~cm}$ accuracy.

\subsection{Shape of the curve across the hips - calculation of hip curve distance (HCD)}

Additionally, we calculated a hip curve distance to present a shape of the curve across the hips to fit the measured additional girth $11 \mathrm{~cm}$ below the waist. First, a basic block pattern of the skirt (Figure 6) was developed based on a model presented by Stiegler and Krolopp [21, page 14]. Front and back pattern cuts of the skirt had the same width (half of the maximum hip girth plus $0,5 \mathrm{~cm}$ ease). The skirt had four darts (two front and two back) formed with a straight line. The length of the front darts was $10 \mathrm{~cm}$ with a width of $2 \mathrm{~cm}$ and the length of the back darts was $17 \mathrm{~cm}$ with a width of $4 \mathrm{~cm}$. The width of the front pattern cut on the waist level was half of the waist girth plus $4 \mathrm{~cm}$ (2 front darts) and at the additional level was half of the additional girth plus $1,4 \mathrm{~cm}$. The width of the back pattern cut at the waist level was half of the waist girth plus $8 \mathrm{~cm}(2$ back darts) and at the additional level half of the additional girth plus $1,4 \mathrm{~cm}$. The shape of the curve across the hip at the side seam was the same for the front and the back pattern cut. At a height of $11 \mathrm{~cm}$ below the waist line, the width of the rest of the back dart was $1,4 \mathrm{~cm}$. Hip curve distance was calculated as the distance from the point $\mathrm{D}$ (on the straight line between the waist (A) and the maximum hip point (B)) and point $\mathrm{C}$ on the side seam following the line of the curve of additional girth. All calculations were made for one side on one block pattern, representing one quarter of the girth.

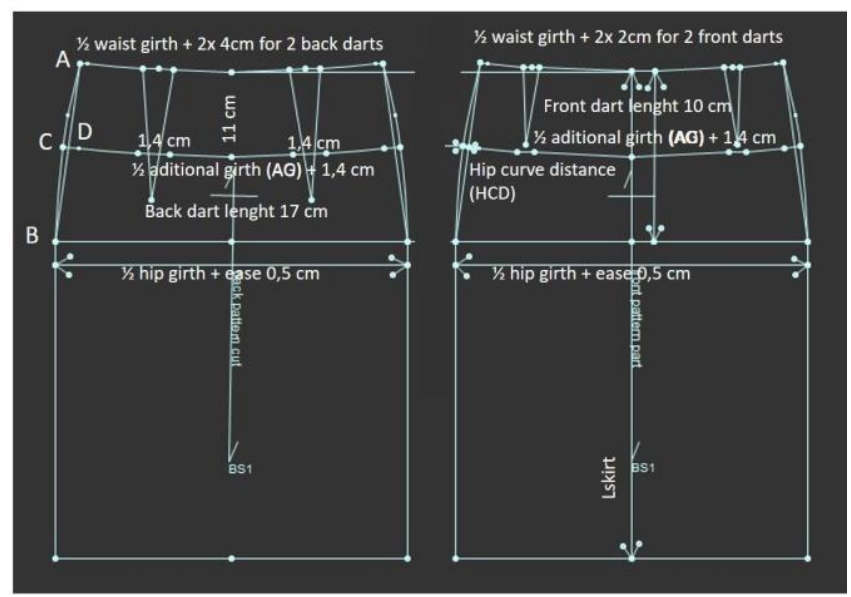

Figure 6. Basic block pattern of the skirt on which HCD was statistical obtained

\subsection{Statistics}

Six groups of subjects were formed following EN 13402-3 standard (SIST EN 13402-3:2017) [29] and labeled with sizes according to (maximum) hip girth from 88 to 108 with increments of 4, more specifically: size 88 (from 86.5 to 90 $\mathrm{cm}$ ), size 92 (from $90.5 \mathrm{~cm}$ to $94 \mathrm{~cm}$ ), size 96 (from 94.5 $\mathrm{cm}$ to $98 \mathrm{~cm}$ ), size 100 (from 98,5 to $102 \mathrm{~cm}$ ), size 104 (from 102,5 to $106 \mathrm{~cm}$ ), and size 108 (from 106,5 to 110 $\mathrm{cm})$. For each group, the basic statistical parameters of the analyzed variables were calculated. The statistical significance of differences among the size groups for single 
variables was first tested with one-way tests ANOVA and then with post-hoc T-tests for single pairs of size groups with Bonferroni correction. Results were statistically processed using SPSS (version 27, IBM SPSS, New York, USA). The Alpha error was set to 5\% (two-tailed).

\section{RESULTS AND DISCUSSION}

\subsection{Results}

The results of measured stature (S), waist girth (WG), maximum hip girth (MaxHG), the additional girth (AG), waist to maximum hip girth distance (WtoMaxHGD as waist height (WH) minus maximum hip girth height (MaxHGH)) and hip curve distance (HCD) are presented in Table 1. The mean waist girth for the entire sample was $68,73 \mathrm{~cm}(\mathrm{SD} 5,49 \mathrm{~cm}$ ) with a range from $60 \mathrm{~cm}$ to $88 \mathrm{~cm}$. For the maximum hip girth, the mean value was $96,75 \mathrm{~cm}$ (SD 5,63 cm) and the range spanned over 6 sizes according to the EN 13402-3. The mean value for additional girth measured $11 \mathrm{~cm}$ below the waist line was $82,88 \mathrm{~cm}$ (SD $5,82 \mathrm{~cm}$ ) and the range was from $71 \mathrm{~cm}$ to $99 \mathrm{~cm}$. The mean vertical distance between the waist line and the maximum hip girth lines (WtoMaxHGD) was $24,14 \mathrm{~cm}$ (SD 2,19 cm) with the range between $18 \mathrm{~cm}$ and $29 \mathrm{~cm}$. The calculated hip curve distance ranged from $-1,41 \mathrm{~cm}$ to $3,36 \mathrm{~cm}$ with a mean value of $0,93 \mathrm{~cm}(\operatorname{SD~} 0,90 \mathrm{~cm})$.

Descriptive statistics for MaxHG and HCD for single size groups are presented in Table2. The values for MaxHG denoted the fact that the minimum and maximum values were according to the size group ranges $(4 \mathrm{~cm})$ and that the mean values corresponded well to the centers of the groups. There were different numbers of subjects present in the groups, from 9 to 47 subjects. The distribution of the subjects to the groups approximately followed the normal distribution with a positive skewness $(0,356)$ and a negative kurtosys (-0.567). The mean hip curve distance in single size groups ranged between $0,59 \mathrm{~cm}$ and $1,33 \mathrm{~cm}$. The ANOVA showed statistical differences among the means ( $p$ $=0,018$ ), but post-hoc t-tests with Bonferroni correction didn't point to any specific pair of groups, likely due to the large ranges between the minimum and the maximum values inside the groups. Although not statistically significant, the mean values and the ranges increased slightly as the size group increased.

\subsection{Discussion}

The main findings of this research showed that (i) the parameter HCD aimed to describe the curvature of the side seam of the basic skirt block pattern varied significantly, (ii) the mean differences in HCD among the size groups were not statistically significant, although they increased according to the size groups, and (iii) the newly introduced measure (AG) was essential for a better fit of the basic block skirt or trousers pattern.

Table 1. Values of the measured S, WG, MaxHG, AG, WtoMaxHGD and HCD of the young slovenian adults

\begin{tabular}{lccccc}
\hline Variable & N & Min $(\mathbf{c m})$ & Max $(\mathbf{c m})$ & Mean $(\mathbf{c m})$ & Std. Deviation \\
\hline age & 162 & 18,0 & 27,0 & 21,44 & 2,07 \\
S & 162 & 157,5 & 176,0 & 167,80 & 3,28 \\
WG & 162 & 60,0 & 88,0 & 68,73 & 5,49 \\
MaxHG & 162 & 85,0 & 110,0 & 96,75 & 5,63 \\
AG & 162 & 71,0 & 99,0 & 82,88 & 5,82 \\
WtoMaxHGD & 162 & 18,0 & 29,0 & 24,14 & 2,19 \\
HCD & 162 & $-1,41$ & 3,36 & 0,93 & 0,90 \\
\hline
\end{tabular}

S-statue, WG-waist girth, MaxHG-maximum hip girth, AG-additional girth, WtoMaxHGD-waist to maximum hip girth distance, HCDhip curve distance

Table 2. Values of the measured S, WG, MaxHG, AG, WtoMaxHG and HCD expressed in centimeters

\begin{tabular}{|c|c|c|c|c|c|c|c|c|c|}
\hline \multirow{2}{*}{ Variable } & \multirow{2}{*}{$\begin{array}{l}\text { Size } \\
\text { group }\end{array}$} & \multirow{2}{*}{$\mathbf{N}$} & \multirow{2}{*}{$\begin{array}{c}\text { Mean } \\
(\mathrm{cm})\end{array}$} & \multirow{2}{*}{$\begin{array}{l}\text { SD } \\
(\mathrm{cm})\end{array}$} & \multirow{2}{*}{$\begin{array}{l}\mathrm{SE} \\
(\mathrm{cm})\end{array}$} & \multicolumn{2}{|c|}{$\begin{array}{l}5 \% \text { Confidence Interval } \\
\text { for Mean }\end{array}$} & \multirow[b]{2}{*}{$\operatorname{Min}(\mathbf{c m})$} & \multirow{2}{*}{$\operatorname{Max}(\mathbf{c m})$} \\
\hline & & & & & & $\begin{array}{l}\text { Lower } \\
\text { Bound }\end{array}$ & $\begin{array}{l}\text { Upper } \\
\text { Bound }\end{array}$ & & \\
\hline \multirow[t]{6}{*}{ MaxHG } & 88 & 18 & 88,36 & 1,03 & 0,24 & 87,85 & 88,87 & 87,0 & 90,0 \\
\hline & 92 & 40 & 92,53 & 1,19 & 0,19 & 92,15 & 92,90 & 90,5 & 94,0 \\
\hline & 96 & 47 & 96,46 & 1,11 & 0,16 & 96,13 & 96,78 & 95,0 & 98,0 \\
\hline & 100 & 29 & 100,50 & 1,26 & 0,23 & 100,02 & 100,98 & 98,5 & 102,0 \\
\hline & 104 & 19 & 104,18 & 1,17 & 0,27 & 103,62 & 104,75 & 102,5 & 106,0 \\
\hline & 108 & 9 & 108,61 & 1,24 & 0,41 & 107,65 & 109,57 & 106,5 & 110,0 \\
\hline \multirow[t]{6}{*}{ HCD } & 88 & 18 & 0,59 & 0,66 & 0,16 & 0,26 & 0,92 & $-1,03$ & 1,59 \\
\hline & 92 & 40 & 0,71 & 0,74 & 0,12 & 0,47 & 0,95 & $-1,41$ & 2,07 \\
\hline & 96 & 47 & 0,90 & 0,95 & 0,14 & 0,62 & 1,18 & $-0,83$ & 3,36 \\
\hline & 100 & 29 & 1,26 & 0,92 & 0,17 & 0,91 & 1,61 & $-0,43$ & 2,80 \\
\hline & 104 & 19 & 1,33 & 0,92 & 0,21 & 0,89 & 1,77 & $-0,29$ & 2,82 \\
\hline & 108 & 9 & 1,10 & 0,90 & 0,30 & 0,41 & 1,80 & 0,25 & 3,26 \\
\hline
\end{tabular}


Differences in HCD distances affected the shape of the curve at the side seam of the skirt or trousers. The higher the HCD value is, the more convex the curve becomes at the level of the measurement of the additional girth between the waist and the maximum hip girth level. A high range of HCD showed that the young female population in Slovenia had very different hip shapes, which was expressed in the form of different curves of the waist and hips from the front view. Negative results of HCD measurements showed the shape of a curve with a combination of convex and concave shape, often associated with more strongly convex thighs below the maximum hip level from the front view. This means that a well-fitting skirt must consider all 3D body shapes that the skirt covers, including the shape of the thighs.

In such cases, the pattern developer would need an additional body circumference somewhere in the middle between the waist and the maximum hip girth to more accurately determine the whole curve of the hips. Such an adjustment would be a good solution for smaller companies making custom clothing. For mass production, a solution to cover a large number of different body shapes within the same shape of the basic pattern block is needed. One possible solution could be to select 1 or 2 standard deviations above the mean value of the HCD within the selected size group, as shown in Table 2. In this way, the clothing companies would cover about $84 \%$ or $98 \%$ of the population, respectively. For customers who would not be satisfied with the deviation of the garment's side seam from their body shape, retailers could offer a side seam alteration, which would be relatively quick and inexpensive.

Knowing the data of additional girth between the waist and the maximum hip girth line can be important for different manufacturers. Especially for those who develop new clothing collections for skirts and trousers, but also for other manufacturers of textile products such as lingerie and others. HCD distance is important information for qualitative assessment of dimensional suitability of clothing for the average body of the selected target group using ready-made mannequins (tailor's dummies) or live models. With the development of computer software for anthropometric measurements, with its ability to capture and processing a wide range of information about dimensions, shapes and postures of real user bodies immediately, it would be useful to introduce new body measures into anthropometric research for clothing. For example, to improve the pattern block for the classic skirt or trousers, one could include information about the girts above body waist height for skirts with higher waist belt height; optimally fitted darts for target customer groups; the slope of the buttocks and abdomen for the length and width of the waist darts, etc. Since clothing is designed for people to wear, individual anatomical variations inevitably affect the fit, drape and silhouette of garments [30]. Development of clothing pattern blocks better adapted to the real body dimensions of specific target groups of customers would increase customer's satisfaction with garments and ensure better sales.

\section{CONCLUSION}

HCD distance significantly influenced the shape of the side seam curve between waist and maximum hip girth levels. It varied significantly from $0,56 \mathrm{~cm}$ to $1,33 \mathrm{~cm}$ in mean values (absolute range $-1,41$ and $3,36 \mathrm{~cm}$ ) among the size groups of Slovenian young female adults. This indicates a large variability in the shape of the side seam across the hips in this population and very like in others as well. Introducing the newly proposed measure of additional girth (AG) between the waist and the maximum hip girth level enabled the calculation of HCD. Although the mean differences in HCD among size groups were not statistically significant, they should not be neglected. Knowledge of the HCD would allow garment production companies to develop basic block patterns more customized to the body shapes. For mass production, a distribution of HCD values would allow an estimation of the shape of the side seam across the hips to satisfy most of the customers. For those who are not satisfied with the deviation of the garment's side seam from the shape of their body, retailers could offer a side seam alteration that would be relatively quick and inexpensive. With the project of anthropometric measurement of the segmented Slovenian population, a measurement tables will be formed, which will provide domestic and foreign producers information about the real dimensions and shapes of the bodies of the modern Slovenian generations. Something similar can be expected in other countries.

A limitation of the present study was a rather small sample to present a structured young female population. Additionally, the participants were only the students from the University of Ljubljana. With a larger sample, the mean HCD differences between size groups could become statistically significant, which would add weight to the results of the present study.

\section{REFERENCES}

1. Podbevšek, T., 2001. Interakcija kroja in telesa - oblikovanje strukturalnega in funkcionalnega sklopa oblačil (Unpublished doctoral dissertation). University of Ljubljana, Faculty of Natural Sciences and Engineering, Department of Textiles, Ljubljana, Slovenia.

2. Katzmarzyk, P. T., William R. L. 1998. Climatic influences on human body size and proportions: ecological adaptations and secular trends. American Journal of Physical Anthropology, vol. 106, no. 4, pp 483-503. 
3. Starc, G., Strel J. 2000. Is there a rationale for establishing Slovenian body mass index references of school-aged children and adolescents. Anthropological Notebooks, vol. 17, no. 3. pp 89-100.

4. Lee, Y. 2018, August. The Definition and Generation of Body Measurements (ISO 8559 Series of Standards). In: Proceedings of the 20th Congress of the International Ergonomics Association. Florence, Italy. pp 405-422.

5. Musilova, B., Nemčokova, R., 2017, September. Study of Czech male body dimension and evaluation of men's trousers patternmaking methods. In: Book of abstracts of the 9th Central European Conference, Liberec, Czech Republic.

6. Podbevšek, T. 2014. For a good fitted skirt, waist to hip distance should be measured. Anthropological Notebooks, vol. 20, no.2, pp 77 88 .

7. Musilova, B., Nemčokova, R., 2014. "Study of czech male body proportions and evaluatinon of men's shirt pattern making methods", Tekstil ve Konfeksiyon, vol.24 no 4 pp 399-404.

8. Bahadır Ünal, Z., 2020. “An Investigation On Suit Choices of Men with Muscular Body Structure", Tekstil ve Konfeksiyon, vol.30 no 4 pp.296-301.

9. Bahadır Ünal, Z., 2017. "A Study on intermediary pattern size focused for children with overweight", Tekstil ve Konfeksiyon, vol.27 no 1 pp.83-90.

10. Beazly, A. 1997. Size and fit: procedures in undertaking a survey of body measurements. Journal of Fashion Marketing and Management, vol. 2, no. 1, pp. 55-85

11. Bolstad, G., Bibba Benum \& Aase Rokne. 2001. Anthropometry of Norwegian light industry and office workers. Applied Ergonomics, Vol. 32, no. 3, pp. 239-46.

12. Hsu, Chih-Hung. 2009. Developing accurate industrial standards to facilitate production in apparel manufacturing based on anthropometric data. Human Factors and Ergonomics in Manufacturing \& Service Industries, vol. 19, no. 3, pp. 199-211.

13. Kilic, A., Öndoga, Z., 2016, Evaluating and defining body measurements according to anthropometric measurerement technique for lower garment pattern preparation, Tekstil ve Konfeksiyon, vol.26 no. 1 pp. 109-116.

14. Podbevšek, T. (Simončič, B.). 2006, June. Anthropometric measuremetn methodology of the trousers' length. In: ISNT - Book of proceedings of the 37th International Symposium on Novelties in Textiles, Ljubljana, Slovenia. pp

15. Podbevšek, T., (Zimšek, D.). 2005, June. Market segmentation in the light of clothing anthropometry. In: AUTEX 2005 - Book of Proceedings of the 5th World Textile Conference, Portorož, Slovenia. pp 671-676.
16. Fan, J., Yu W., Hunter L. 2004, Clothing apperarance and fit : Science and technology, Cambridge: Woodhead Publishing Limited, 31-42.

17. Aleksander, M., Jo Connell, L., Beth Presley, A. 2005. Clothing fit preferences of young female adult customers. International Journal of Clothing and Technology. vol.17, no.1, pp 52-64.

18. Ashdown, S. P., Dunne, L. 2006. A study of automated custom fit: readiness of the technology for the apparel industry. Clothing Textile Research Journal, vol. 24, pp 121-36.

19. Tama, D., Ondogan Z. 2014. Fitting Evaluation of Pattern Making Systems According to Female Body Shapes.Fibres and Textiles in Eastern Europe, vol.22, no.4, pp.107-111.

20. Stiegler, M., Krolopp, L. 1996. Schnittkonstruktionen für Röcke und Hosen. München, Rundschau-Verlag Otto G. Königer GmbH \& Co, pp.14.

21. Aldrich, W. 2004. Metric Pattern Cutting. Oxford, Blackwell Science, pp.56

22. Mors De Castro, L. 2010. Patternmaking in Fashion - Step by Step. Köln, Evergreen GmbH.

23. Szabás, F. 1983. Női szabó szakrajz, Budapest, Müszaki Könyvkiadó, pp. 11 .

24. Wargnier, C. (Collectif Esmond Paris). 2009. Become a Pattern Drafter-Womens's garments, Vol.1. Esmod Editions, pp.15.

25. Mors De Castro, L. 2010. Patternmaking in Fashion. Evergreen, pp.36.

26. Holman, G. 2004. Pattern Cutting Made Easy. B.T.Batsford Ltd, pp.8-9.

27. Joseph-Armstrong, H. 2006. Patternmaking for Fashion Design, Pearson Prentice Hall, pp. 44.

28. ISO 8559-1:2017 (E): Size designation of clothes - Part 1: Anthropometric definitions for body measurement. International Organization for Standardization. Geneve, Switzerland, 2017, 80 pp.

29. EN 13402-3:2017 (E): Size designation of clothes - Part 3: Body measurements and intervals. European Committee for Standardization, Brussels, 2017, 36 pp.

30. Liu, C., Kennon, R. 2003. Comparison of English and Chinese Clothing Pattern Systems. Research Journal of Textile and Apparel, vol.7, no.1, pp.49-61. 